\title{
A PROSPECTIVE RANDOMISED STUDY ON POST-OPERATIVE DRAINS IN THYROID SURGERIES
}

\author{
Ramula Muthammal ${ }^{1}$, Pandian Periyasamy ${ }^{2}$
}

${ }_{1}^{1}$ Associate Professor, Department of Surgery, Government Chengalpattu Medical College, Chengalpattu, Tamilnadu, India. ${ }^{2}$ Assistant Professor, Department of Surgery, Government Chengalpattu Medical College, Chengalpattu, Tamilnadu, India.

\section{BACKGROUND} ABSTRACT

Post-operative drains in thyroid surgery are commonly used to avoid haematomas. This study was undertaken to find out the routine placement of drains necessary in thyroid surgeries. This study was conducted in two groups of 50 patients each with and without drains and results compared. Both groups were homogeneous in all aspects.

Aim- This prospective clinical trial was conducted to evaluate the routine use of drains after thyroidectomy (total and hemi) for benign thyroid disorders.

\section{MATERIALS AND METHODS}

A total of 50 patients of thyroidectomy were randomly chosen not to be drained from June 2014 to August 2015 in our institution, the Government Chengalpattu Medical College and Hospital. Outcomes including operating time, post-operative pain, hospital stay, complications, necessity for re-operation and satisfaction of patients were all assessed and compared with 50 randomly chosen patients to be drained.

\section{RESULTS}

There was no significant reduction in the operating time. The post-operative pain/ discomfort was found to be significantly low assessed by visual analogue scale. Four cases of seroma were seen, which were treated conservatively. No patient needed reoperation for any complication. The mean hospital stay was shorter, and the satisfaction of patients was significant.

\section{CONCLUSION}

The findings suggest that post-operative complications cannot be significantly prevented by routine use of drains. Furthermore, the use of drains may increase post-operative pain subsequently requiring analgesic, surgical site infection and prolong the hospital stay. In the light of these findings, the routine use of drains may be deemed not routinely necessary following thyroid surgeries.

\section{KEY WORDS}

Thyroidectomy Complications, Drains, Post-Operative Pain, Seroma.

HOW TO CITE THIS ARTICLE: Muthammal R, Periyasamy P. A prospective randomised study on post-operative drains in thyroid surgeries. J. Evolution Med. Dent. Sci. 2018;7(40):4340-4342, DOI: 10.14260/jemds/2018/968

\section{BACKGROUND}

Thyroidectomy is one of the most commonly performed operative procedures in general surgery in our institution. Until recently, surgeons routinely used drains after thyroidectomy. The logic is to drain a possible post-operative haemorrhage, which may compress the air passages and produce respiratory embarrassment. ${ }^{1}$ Haemorrhage might be life-threatening and require immediate re-operation. This apprehension led the surgeons to use drains after any type of thyroid surgery. Bergqvist and Kallero (1985) analysed the re-operated cases for post-operative haemorrhage after thyroid surgery and they could not find any benefit of drainage. They also suggested that drains may block with clotted blood and do not serve the purpose even if major bleeding occurs. ${ }^{2}$ Few other studies have also failed to show any benefit of drainage in thyroid surgery (Hurtado-López et al 2001; Suslu et al 2006). On the other hand, drains might increase the rate of surgical wound infections. ${ }^{3}$

'Financial or Other Competing Interest': None.

Submission 21-06-2018, Peer Review 13-09-2018,

Acceptance 21-09-2018, Published 01-10-2018.

Corresponding Author:

Dr. Ramula Muthammal,

A-14, Old G.S.T. Road,

Alagesan Nagar, Chengalpattu-603001,

Tamilnadu, India.

E-mail: ramuladurai@gmail.com DOI: $10.14260 /$ jemds $/ 2018 / 968$
(Ariyanayagam et al, 1993; Tabaqchali et al, 1999), contribute to the discomfort of the patients (Peix et al, 1992), prolong the length of the hospital stay and thereby increase the cost (Suslu et al, 2006) and cosmetically disfiguring (Clark et al, 2002). Several other authors have questioned the usefulness of routine drainage. ${ }^{4}$ Use of drain does not reduce the reoperation rate also reported in many studies. In addition, drain may increase the duration of hospital stay and the cosmetic results may not be as good as in non-drained patients. 5

Our study was designed to evaluate the advantages of non-usage of drains routinely following Thyroidectomy.

\section{MATERIALS AND METHODS}

\section{Study Design}

A prospective, longitudinal, comparative, randomised study.

The randomised, prospective study was conducted in tertiary care hospital between June 2014 and August 2015. The sample size was taken for convenience. 100 patients undergoing total or hemi-thyroidectomy for thyroid disorders during this study period were enrolled in this study after getting written informed consent. Patients enrolled randomly assigned to apply drains $n=50$ and no drain $n=50$, randomly chosen by computer analyst.

Post-operative complications including pain by VAS, postoperative wound collection based on USG, infection, sarcoma, haematoma and duration of hospital stay all recorded. 
The 50 non-drained patients in study group compared with 50 patients from other units who were drained. Patients with Graves' disease and malignant thyroid disorders were excluded.

Total thyroidectomy was performed by the standard technique. Informed consent was obtained from all the patients and procedure, results and complications discussed. We prefer a slightly higher skin crease incision since we reckon control of superior pedicle is somewhat more difficult than the inferior. And we cut the strap muscles more liberally than usual.

The operating time, post-operative pain, (assess by visual analog scale from no pain to severe pain $(0=10)$ and mean score compared in both groups) analgesic administration, hospital stay, complications such as wound infection, seroma, bleeding, haematoma, inferior laryngeal nerve/ external laryngeal nerve palsy or hyperparathyroidism and necessity for re-operation were all recorded. The operating time was recorded from the placement of skin incision to the last skin closing suture/ clip. Oral acetaminophen alone or in combination with ibuprofen was used if the score was under 5 and intramuscular diclofenac or tramadol hydrochloride was used for scores more than 5 . The quantity and the type of analgesic used for each patient was recorded. The patients were discharged once they were comfortable as assessed by their own words, usually between the 3rd and 6th POD.

\section{Statistical Analysis}

The data were entered in MS Excel and analysed in SPSS software version 16 . The descriptive statistics were calculated as frequency and percentage. Proportion test was used to find difference between groups at 5\% level of significance. Differences between the two groups were analysed with $\mathrm{x}^{2}$ test results were expressed as mean and SD. Student's ' $t$ ' test used for age, hospital stay, operating time and complications were analysed.

\section{RESULTS}

\begin{tabular}{|c|c|c|}
\hline Complications & Non-Drained & Drained \\
\hline Haematoma & $1(2 \%)$ & $2(4 \%)$ \\
\hline Seroma & $1(2 \%)$ & $3(6 \%)$ \\
\hline Wound infection & $0(0 \%)$ & $1(2 \%)$ \\
\hline $\begin{array}{c}\text { Suture reaction } \\
\text { Transient recurrent nerve } \\
\text { proxy }\end{array}$ & $1(2)$ & $2(4 \%)$ \\
\hline $\begin{array}{c}\text { Persistent recurrent nerve } \\
\text { injury }\end{array}$ & $0(0 \%)$ & $0(0 \%)$ \\
\hline $\begin{array}{c}\text { Transient } \\
\text { hypoparathyroidism }\end{array}$ & $2(4 \%)$ & $3(6 \%)$ \\
\hline $\begin{array}{c}\text { Persistent } \\
\text { hypoparathyroidism }\end{array}$ & $0(0 \%)$ & $0(0 \%)$ \\
\hline
\end{tabular}

Table 1. The data are presented as the Number of patients and Percentiles in parenthesis; $X^{2}$ test was done for all the Complications

*P value was presented for the total complications number. Post-operative complications ( $\mathrm{P}>0.05^{*}$ ).
The data is presented as the number of patients with percentiles in parenthesis. A Chi-square test was used for all the complications.*

\begin{tabular}{|lclr|}
\hline & Group 1 & Group 2 & P \\
\hline$*$ Operating time (min) & $116.45(70-120) \pm 18.93$ & $118.80(65-120) \pm 21.33$ & 0.19 \\
${ }^{*}$ Thyroid volume (ml.) & $54.31(17.3-116.4) \pm 22.48$ & $53.72(16.8-120.4) \pm 21.61$ & 0.80 \\
$*$ Postoperative sixth hour & $3.64(2-7) \pm 1.06$ & $4.95(2-8) \pm 1.05$ & 0.002 \\
$\quad$ VAS & & $3.09(1-5) \pm 0.77$ & 0.001 \\
**Postoperative first day & $2.08(1-5) \pm 0.74$ & $1.53(1-6) \pm 0.80$ & 0.04 \\
$\quad$ VAS & $1.10(1-3) \pm 0.33$ & & \\
*Hospital stay (day) & &
\end{tabular}

Table 2. Operative and Post-Operative Values of the Patients

VAS: Visual Analog Scale. The data is presented as mean (min - max) \pm SD. *Student's t-test was used for assessment. ${ }^{* *}$ The Mann-Whitney U test was used for assessment.

\begin{tabular}{|c|c|}
\hline Group $1(\mathrm{~N}=50)$ & Group $2(\mathrm{~N}=50)$ \\
\hline $4.09(0-25) \pm 6.08 \mathrm{~mL}$ & $3.64(0-30) \pm 5.07 \mathrm{~mL}$ \\
\hline \multicolumn{2}{|c|}{$\mathrm{P}=0.11$} \\
\hline Group 1 & Group 2 \\
\hline Nontoxic $(N=50)$ & Nontoxic $(N=50)$ \\
\hline $4.38(0-18.4) \pm 4.14$ & $4.39(0-25)+4.26$ \\
\hline $\mathrm{P}=0.19$ & $\mathrm{P}=0.16$ \\
\hline
\end{tabular}

Table 3. Volume of Fluid Collection in the groups as Assessed by USG

The data is presented as mean (min - max) \pm SD. Student's t-test was used for assessment.

The drained group consisted of 38 females and 12 males with mean age of $(37+10.7$ yrs. $)$. The non-drained group comprised of 15 men and 35 women with a mean age of $(39+10.6$ yrs.). There was no significant difference in the gender, age, hormonal status and histopathological results of the patients between the two groups $(\mathrm{p}=0.27, \mathrm{p}=0.56$, $\mathrm{p}=0.24, \mathrm{p}=0.42$ ) respectively.

The mean operating time was similar in drained patients $[118+21.33 \mathrm{mts}]$ and for non-drained patients it was $116+18.93 \mathrm{mts}]$. The mean VAS score was significantly reduced more in the non-drained group than the drained group patients in POD 0 and a similar result was obtained in POD 1 when we compared the non-drained group with the drained. In addition, the mean amount of intramuscular analgesic requirement was significantly less in the nondrained group than in the drained group.

The complication rates were substantially lower in the non-drained group. 1 case of seroma (2\%) and 2 cases of transient hypoparathyroidism (4\%) and no case of wound infection occurred in the non-drained group. Ariyanayagam et al 1993 in their study noted discomfort and wound infections more in drained group. Sulu et al 2006 in their study showed drain failed to show any benefit over nondrained group whereas one case of haematoma (2\%), two cases of seroma (4\%), two cases of wound infections (4\%) and two cases of transient hypoparathyroidism (4\%) occurred in the drained group. No patient needed surgical revision or re-operation for any complication and all 
complications were successfully managed conservatively. 13 patients were discharged on day 1; 26 patients on day 2 and 11 patients were discharged from day 3 to 5 in the nondrained group. While none were discharged on Day 1 or 2 in the drained group. In our study the mean duration of hospital stay after thyroidectomy of the no drain group is significantly less than drain group, and cosmetically better scar in no drain group. Patients with drain had pain as assessed by VAS in no drain group patients, comfortable even on first postoperative day. Though drains are kept to detect postoperative bleeding, in some cases the drain is self-blocked by haemorrhage as reported in many clinical studies and well documented by Woods et al.

\section{DISCUSSION}

Drains are routinely used in our surgical clinics after thyroid surgery. The use of drains is based on traditions rather than scientific evidence and dependent on the surgeon's experiences and training 6 (Defechereux et al, 1997). The main expectation for drains usage is to prevent post-operative complications to alert the surgeon to early post-operative bleeding (Wihlborg et al, 1988). Whilst drain usage might be omitted in non-complicated cases because drainage is very low and might be not necessary or because adequate haemostasis can never be replaceable by using drains. ${ }^{7}$ In the case of incomplete drainage, seroma or haematoma would be the unavoidable conclusion (Karayacin et al, 1997; Peix et al, 1992; Ruark and Abdel-Misih, 1992).

Woods et al in their meta-analysis documented increased wound infection rate, prolonged hospital stay and postoperative pain in patients who underwent thyroidectomy with drains or drains might be associated with possible infection (Ariyanayagam et al, 1993; Kristoffersson et al, 1986; Teboul et al, 1992). Surgical techniques for benign thyroidal disorders have improved greatly and postoperative morbidity and mortality rates have decreased significantly. ${ }^{8}$ Life-threatening complications such as postoperative bleeding, haematoma, compression of air passages or suffocation, can be avoided in most patients (Colak et al, 2004; Müller et al, 2001). With the above arguments, the routine usage of drains following thyroid surgeries has been questioned.

Various randomised trials have failed to answer this question in its entirety. Most of these studies revealed that drainage is unnecessary after routine thyroid surgery ${ }^{9}$ (Hurtado-López et al, 2001; Khanna et al, 2005). Perfect haemostasis helps in avoiding haematoma formation postoperatively and reduces the incidence of wound infection. ${ }^{10}$

In our study, only the patients who underwent thyroid surgeries for benign disorders were included. Serious haemorrhage did not occur in any patient. But minimal haematoma was diagnosed in one patient in the drained group, which was evacuated by removing the sutures. The drains were removed mostly after the second POD, which deterred discharge of the patients until then. The pain and discomfort caused by the drain per se was clinically obvious, which necessitates the use of prolonged analgesic administration in these drained groups. There was one case of wound infection in the drained group, which we could not authentically say was due to the drains. On the other hand, there were no such complication in the non-drained group. With the introduction of new surgical equipment and advance in technology the incidence of haematoma is less common, hence routine use of drains in thyroid surgery not recommended in many recent studies. ${ }^{11}$ Though drains can prevent any collection in the thyroidectomy bed, negative suction drained reported to cause irritation to adjacent blood vessels, lymphatics leading to haemorrhage and seroma. ${ }^{12}$

\section{CONCLUSION}

Our prospective study concluded that routine use of drains in the patients undergoing thyroid surgeries may be deemed no more mandatory due to the fact that there was a significant reduction in the hospital stay, decreased post-operative pain and no significant benefit was observed in the prevention of seroma or haematoma formation. No drain thyroid surgeries reduce the post-operative hospital stay beneficial to the patient, with better scar and with relatively less discomfort to the patient.

\section{REFERENCES}

[1] Matory YL, Spiro RH. Wound bleeding after head and neck surgery. J Surg Oncol 1993;53(1):17-9.

[2] Teboul F, Peix JL, Guibaud L, et al. Prophylactic drainage after thyroidectomy: a randomized trial. Ann Chir 1992;46(10):902-4.

[3] Chow SC, Shao J, Wang H. Large sample test for proportions. New York: Marcel Dekker 2003.

[4] Kristoffersson A, Sandzen B, Jarhult J. Drainage in uncomplicated thyroid and parathyroid surgery. $\mathrm{Br} \mathrm{J}$ Surg 1986;73(2):121-2.

[5] Colak T, Akca T, Kanik A, et al. Total versus subtotal thyroidectomy for the management of benign multinodular goiter in an endemic region. ANZ J Surg 2004;74(11):974-8.

[6] Defechereux T, Hamoir E, Dang ND, et al. Drainage in thyroid surgery. Is it always a must? Ann Chir 1997;51(6):647-52.

[7] Khanna J, Mohil RS, Chintamani, et al. Is the routine drainage after surgery for thyroid necessary? A prospective randomized clinical study [ISRCT N63623153]. BMC Surg 2005;5(1):11-3.

[8] Shaha AR, Jaffe BM. Practical management of postthyroidectomy hematoma. J Surg Oncol 1994;57(4):235-8.

[9] Suslu N, Vural S, Oncel M, et al. Is the insertion of drains after uncomplicated thyroid surgery always necessary? Surg Today 2006;36(3):215-8.

[10] Tabaqchali MA, Hanson JM, Proud G. Drains for thyroidectomy/parathyroidectomy: fact or fiction? Ann R Coll Surg Engl 1999;81(5):302-5.

[11] Wihlborg 0, Bergljung L, Martensson H. To drain or not to drain in thyroid surgery. A controlled clinical study. Arch Surg 1988;123(1):40-1.

[12] Ariyanayagam DC, Naraynsingh V, Busby D, et al. Thyroid surgery without drainage: 15 years of clinical experience. J R Coll Surg Edinb 1993;38(2):69-70. 